\title{
Asian Journal of Life Sciences
}

\section{Prevalence of Extend Spectrum Beta Lactamases Producing Enter- obacteriaceae and their Antibiotic Susceptibility in Lomé, Togo}

\author{
Akouétévi Gérard Toudji ${ }^{1,3}$, Bouraïma Djeri', Simplice D Karou ${ }^{* 1}$, Ségla Tigossou ${ }^{2,3}$, Yaovi Ameyapoh ${ }^{1}$, Comlan de Souza ${ }^{1}$. \\ ${ }^{1}$ Laboratory of Microbiology and Quality Control of Food stuffs, Ecole Supérieure de Techniques Biologiques et Alimentaire (ESTBA-
} UL) University of Lomé, Togo

${ }^{2}$ Laboratory of Microbiology, CHU-Sylvanus Olympio, Lomé, Togo

${ }^{3}$ Laboratory of Microbiology, Polyclinelle Wossinu and Gbogbo, Lomé, Togo

"Corresponding author: Simplice D Karou. Laboratory of Microbiology and Quality Control of Foodstuffs, Ecole Supérieure de Techniques Biologiques et Alimentaire (ESTBA-UL) University of Lomé, Togo Tel: +00228 9664 8825; E-mail: simplicekarou@, hotmail.com.

Citation: Toudji AG, Djeri B, Karou SD, Tigossou S, Ameyapoh Y, et al. (2017) Prevalence of extend spectrum beta lactamases producing Enterobacteriaceae and their antibiotic susceptibility in Lomé, Togo. Asian J Life Sci 2017: AJLS101. DOI: 10.29011/ AJLS-101.000001

Received Date: 21 March, 2017; Accepted Date: 5 April, 2017; Published Date: 12 March, 2017.

\begin{abstract}
Objective: The aim of this study was to determine the prevalence of Enterobacteriaceae producing Extended Spectrum BetaLactamases (ESBL) and to assess their antibiotic susceptibility.

Materials and Methods: The study included 1377 bacterial strains isolated at the University hospital Sylvanus Olympio and the Polyclinic Wossinu-Gbogbo both in Lomé between 2009 and 2011. The antibiotic susceptibility test was performed agar disk diffusion assay as recommended by the Antimicrobial susceptibility Committee of the French Society for Microbiology. The production of Extended Spectrum Beta-Lactamases was assayed by double-disk synergy technique.

Results: A total of 309 strains produced the ESBLs, a global prevalence of $22.44 \%$. The strain distribution was $35.34 \%$ for Enterobacter sp., 27.84\% Klebsiella sp., 23.76\% for E.coli, 16.30\% for E.coli Alkalescens- Dispar, 14.18\% for Citrobacter sp. and $7.56 \%$ for Proteus $s p$. These strains were more frequently isolated from pus $(47.90 \%)$ followed by urine $(40.78 \%)$. The resistance rates observed with E.coli were respectively $0.68 \%, 1.38 \%$ and $4 \%$ for imipenem, colistin and cefoxitin. Regarding Klebsiella sp., these rates were $3.70 \%, 1.27 \%$ and $4 \%$, respectively.

Conclusion: This study showed that the prevalence of ESBL has reached an alarming level in Lomé. E. coli and Klebsiella $s p$. are the most implicated microorganisms. Nationwide studies are planned to investigate the problem.
\end{abstract}

Keywords: Bacterial strains; Multidrug resistance; Extended Spectrum Beta-Lactamase; Antibiotics.

\section{Introduction}

The emergence and the dissemination of antibiotic resistance constitute a major public health problem $[1,2,3]$. This phenomenon results in an increasing morbidity and mortality from infectious diseases. One approach in the fight against antimicrobial resistance involves the prevalence studies of multi-resistant strains circulating in hospitals and their susceptibility to antibiotics. Thus the studies conducted around the world have mainly complained the
Gram-positive cocci [4] and Gram negative bacteria, including Enterobacteriaceae [2,5]. The Enterobacteriaceae have been found to express a high acquired resistance to the main beta-lactam antibiotics through the production of enzymes called Extended spectrum Beta-Lactamases (ESBLs). These enzymes inactivate cephalosporins of the first, second and third generations [6,7]. The genes encoding for these enzymes are carried by plasmids and coexist with the genes for resistance to other antibiotics [7]. Escherichia coli and Klebsiella pneumoniae were found to be the most implicated bacteria in the expression of ESBLs [8,9]. Hence, from a study conducted in Cameroon, Enterobacteriaceae secreting 


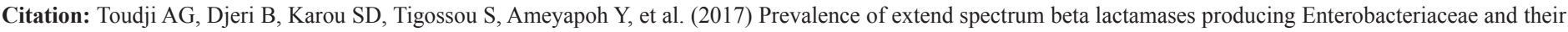
antibiotic susceptibility in Lomé, Togo. Asian J Life Sci 2017: AJLS101.

ESBLs were around $12 \%$, of which $14.3 \%$ E. coli and $18.8 \% \mathrm{~K}$. pneumoniae [10]. In Benin, in the department of Zou and Collines, $22 \%$ strains of $E$. coli were ESBL producing [11]. In Togo, some authors reported the resistance of bacterial strains to some antibiotics, but until now there is a lack of studies addressing exclusively the Extend Spectrum Beta-Lactamases producing bacteria [12,13]. This study therefore aimed to determine the prevalence of Enterobacteriaceae producing Extended Spectrum Beta-Lactamases in two health facilities in Lomé, and to test their susceptibility to several antibiotics.

\section{Materials and methods}

\section{Isolation and identification of bacterial strains}

The bacterial strains were isolated at the University Hospital Sylvanus Olympio and the Polyclinic Wossinu-Gbogbo in Lomé, following the methods in force in the two centers [14,20,21]. The samples were pathologic specimens routinely analyzed in the two centers. These included vaginal swabs, urines, pus and bloods received during the period time from January 2009 to December 2011. For the processing, vaginal swabs, urine and pus samples were directly seeded on the Eosin ethylene Bleu (EMB) agar. The blood samples were used to inoculate vials of blood culture hemoline (Bio Mérieux, France) for at least seven days to detect the bacterial growth. Afterwards, the Gram staining was performed on the subcultures prior to the identification with the API 20E System (Bio Mérieux, France) $[15,16,17]$. Duplicated strains were discarded.

\section{Susceptibility testing and detection of beta lactamases production}

The susceptibility to antibiotics was performed by agar disk diffusion and the results were interpreted following the recommendations of the Antimicrobial susceptibility Committee of the French Society for Microbiology (CA-SFM) [19]. The inhibition zone around each disk was measured and compared to diameters corresponding to inferior critical concentration and superior critical concentration. The categorization criteria are defined as sensitive (S), intermediate (I) and resistant (R) for each antibiotic used $[14,19,23]$. However, all intermediate strains were considered as resistant in this study. A total of 24 antibiotics including amoxicillin $(20 \mu \mathrm{g})$, amoxicillin+clavulanic acid $(20-10 \mu \mathrm{g})$, carbenicillin $(100 \mu \mathrm{g})$, Imipenem $(10 \mu \mathrm{g})$, cephalothin $(30 \mu \mathrm{g})$, cefoxitin $(30 \mu \mathrm{g})$, cefotaxime $(5 \mu \mathrm{g})$, ceftazidime $(10 \mu \mathrm{g})$, ceftriaxone $(30 \mu \mathrm{g})$, gentamicin $(10 \mu \mathrm{g})$ amikacin $(30 \mu \mathrm{g})$, netilmicin $(10 \mu \mathrm{g})$, kanamycin $(10 \mu \mathrm{g})$, chloramphenicol $(30 \mu \mathrm{g})$, colistin $(10 \mu \mathrm{g})$, nalidixic acid $(30 \mu \mathrm{g})$, ciprofloxacin $(5 \mu \mathrm{g})$, pefloxacin $(5 \mu \mathrm{g})$, levofloxacin $(5 \mu \mathrm{g})$, ofloxacin $(5 \mu \mathrm{g})$, norfloxacin $(10 \mu \mathrm{g})$, doxycycline $(15 \mu \mathrm{g})$, tetracycline $(15 \mu \mathrm{g})$ and trimethoprim+sulphamethoxazole $(1.25-23.75 \mu \mathrm{g})$ were tested. The production of ESBL was assayed by the double disk synergy technique described by Jarlier et al. [18]. The Amoxicillin+clavulanic acid disk (AMC) was deposited between third generation cephalosporins (C3G) disks namely ceftazidime, cefotaxime or ceftriaxone at a distance of 2 to $3 \mathrm{~cm}$ on Muller Hinton agar plate. After 18 to 24 hours incubation, the production of ESBL was revealed by the appearance of a characteristically inhibition zone between the AMC disk and those of $\mathrm{C} 3 \mathrm{G}$ referred to as a "champagne-cork".

\section{Statistical analysis}

The percentages of resistance were compared among species on the Epi-info software version 6 by Fisher's test with the statistical significance set at $\mathrm{P}<0.05$.

\section{Results}

\section{Prevalence of ESBL producing strains of Enterobacteri- aceae}

A total of 1377 strains belonging to several genera and species were isolated in the present study. The main genera, contributing with more than 20 strains each, were Escherichia, Klebsiella, Enterobacter, Proteus and Citrobacter. The species from the following genera Shigella, Salmonella, Morganella and Yersinia contributed with less than 20 strains each, this was referred to as other Enterobacteriaceae in (Table 1). At the species level, E. coli and $K$. pneumoniae were the leading agents, accounting for $48.29 \%$ and $23.60 \%$ of the total isolates, respectively. Enterobacter gergoviae and Proteus mirabilis represented $8.13 \%$ and $6.32 \%$, respectively. The other species contributed with less than 5\% (Table 1). The ESBL production was not detected in some species

such as Enterobacter cloacae, Citrobacter freundii and in the genera of Shigella, Salmonella, Yersinia and Morganella referred to us other bacteria in (Table 1). The double disk synergy test showed that 309 of the 1377 strains produced the ESBL, a global rate of $22.44 \%$. These ESBL producing strains were classified by order of importance as follows: Enterobacter gergoviae (36.61\%), K.pneumoniae (28.31\%), E. coli $(23.73 \%)$, E. coli Alkalescens-Dispar (16.13\%), Citrobacter diversus (15.00\%), Klebsiella oxytoca (11.11\%), Proteus mirablis $(8.05 \%)$ and Proteus vulgaris $(7.41 \%)$ (Table 1$)$. 


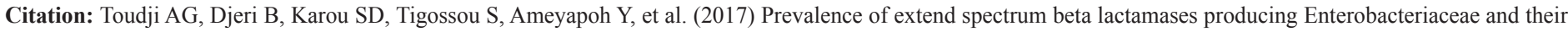
antibiotic susceptibility in Lomé, Togo. Asian J Life Sci 2017: AJLS101.

\begin{tabular}{|c|c|c|}
\hline Species & $\begin{array}{c}\text { Isolated strains } \\
\mathbf{N}(\%)\end{array}$ & $\begin{array}{c}\text { ESBL produc- } \\
\text { ing strains } \\
\mathbf{N}(\%)\end{array}$ \\
\hline Escherichia coli & $665(48.29)$ & $158(23.76)$ \\
\hline Escherichia coli $A-D$ & $31(2.25)$ & $5(16.13)$ \\
\hline Klebsiella pneumoniae & $325(23.60)$ & $92(28.31)$ \\
\hline Klebsiella oxytoca & $9(0.65)$ & $1(11.11)$ \\
\hline Enterobacter gergoviae & $112(8.13)$ & $41(36.61)$ \\
\hline Enterobacter cloacae & $4(0.29)$ & $0(0.00)$ \\
\hline Proteus mirabilis & $87(6.32)$ & $7(8.05)$ \\
\hline Proteus vulgaris & $27(1.96)$ & $2(7.41)$ \\
\hline Citrobacter diversus & $20(1.45)$ & $3(15.00)$ \\
\hline Citrobacter freundii & $1(0.07)$ & $0(0.00)$ \\
\hline Other Enterobacteriaceae & $96(6.97)$ & $0(0.00)$ \\
\hline
\end{tabular}

Table 1: Distribution of isolated ESLM producing Enterobacteriaceae.

Escherichai coli A-D for Escherichia coli Alkalescens-Dispar, The other Enterobacteriaceae for the species of the genera Shigella, Salmonella, Yersinia and Morganella

\section{Main sources of isolation of ESBL producing strains}

Four pathologic products namely the pus, urine, blood and the vaginal swabs were the source of isolation of these ESBL producing Enterobacteriaceae. In the ascending order of contribution, the pathologic products were ranked as follows: vaginal swabs $3.56 \%(11 / 309)$, blood $7.77 \%(24 / 309)$, urine $40.78 \%(126 / 309)$ and pus $47.90 \%(148 / 309)$ (Figure 1).

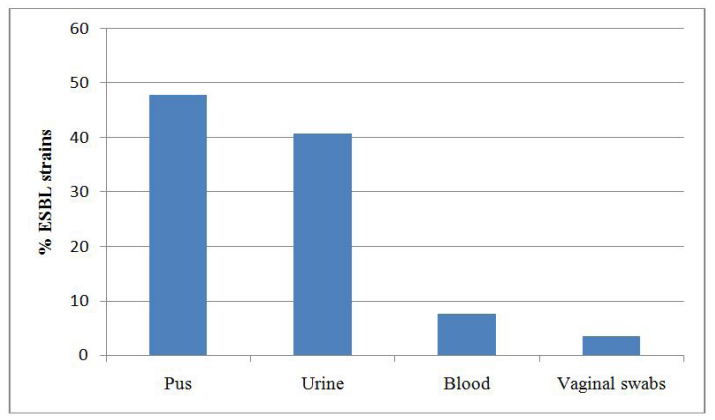

Figure 1: Distribution of ESBL strains among the analyzed samples.

The distribution of bacterial species in the treated samples is presented in (Figure 2).

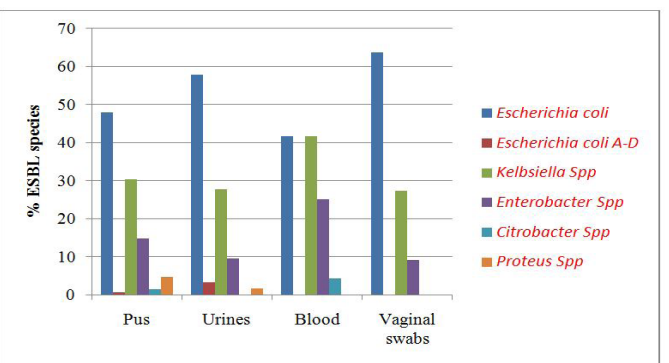

Figure 2: Distribution of bacterial strains among pathologic samples

Globally, E. coli was the most frequently isolated species, by occurring in all the analyzed samples at the following rates $63.64 \%, 57.94 \%, 47.97 \%$ and $41.67 \%$ from vaginal swabs, urine, pus and blood respectively. On the other hand, E. coli A-D was not found in blood and vaginal swabs. This bacterium was found to occur preferentially in urine samples. The species from the genera Klebsiella and Enterobacter were also found in all the analyzed samples. For these microorganisms, blood and pus were the main isolation sources. Citrobacter species were only found in blood and pus while Proteus species were found in pus and urine. Pus samples were the mains source of bacterial isolation by leading to the isolation of all incriminated microorganisms.

\section{Antibiotic susceptibility of the main ESBL producing strains}

(Table. 2) shows the resistance profile of the most represented Enterobacteriaceae namely E. coli, Klebsiella sp., Enterobacter $s p$., Proteus $s p$. and E. coli A-D. All strains were highly resistant to beta-lactams with a maximum rate of $100 \%$. Imipenem, however completely inhibited all the strains of Enterobacter sp, E. coli A-D and Proteus sp., while the strains of E. coli and Klebsiella $s p$. showed a fair resistance with rates of $0.68 \%$ and $3.7 \%$ respectively. These resistance rate were found to be statistically different according to $p$-values $<0.05$ calculated by the Fisher's test. The E. coli A-D strains did not expressed resistance to aminoglycosides tested in this study i.e. amikacin and netilmicin. To these same antibiotics, Proteus $s p$ showed respective resistance rates of $30 \%$ and $40 \%$, in addition to totally resist to gentamicin and kanamycin (100\%). In E. coli, Klebsiella sp and Enterobacter sp, the resistance seemed stratified. It was low against amikacin and high with gentamicin. Enterobacter $s p$. and Proteus $s p$. totally resisted to chloramphenicol, while colistin strongly inhibited all strains accepted Proteus sp. All the tested microorganisms highly resisted to cyclines and sulfonamides (resistance rates above 90\%). 


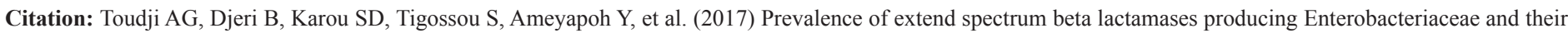
antibiotic susceptibility in Lomé, Togo. Asian J Life Sci 2017: AJLS101.

\begin{tabular}{|c|c|c|c|c|c|c|c|}
\hline $\begin{array}{l}\text { Antibiotic } \\
\text { classes }\end{array}$ & Antibiotics & $\begin{array}{c}E . \text { coli } \\
(N=158)\end{array}$ & $\begin{array}{l}\text { Klebsiella spp } \\
\quad(N=81)\end{array}$ & $\begin{array}{c}E . \text { spp } \\
(N=41)\end{array}$ & $\begin{array}{c}\text { E. coli } \\
A-D(N=5)\end{array}$ & $\begin{array}{c}\text { Proteus } \\
\text { Spp. } \\
(N=9)\end{array}$ & $p$ value \\
\hline \multirow{8}{*}{ Beta-lactams } & Amoxicillin & 100 & 100 & 100 & 100 & 100 & - \\
\hline & & 87.76 & 100 & 100 & 100 & 100 & $<0.001$ \\
\hline & Carbenicillin & 99.2 & 100 & 100 & 100 & 100 & $<0.001$ \\
\hline & Imipenem & 0.68 & 3.7 & 0 & 0 & 0 & 0.016 \\
\hline & Cefalotin & 100 & 98.77 & 100 & 100 & 100 & 0.4 \\
\hline & Cefotaxim & 100 & 100 & 100 & 100 & 100 & - \\
\hline & Ceftazidim & 97.28 & 100 & 100 & 100 & 100 & 0.028 \\
\hline & Ceftriazone & 97.16 & 100 & 100 & 100 & 100 & 0.028 \\
\hline \multirow{4}{*}{ Aminosides } & Gentamicin & 82.2 & 94.64 & 96.3 & - & 100 & $<0.001$ \\
\hline & Amikacin & 13.43 & 4.23 & 2.86 & 0 & 30 & $<0.001$ \\
\hline & Netilmicin & 24.82 & 37.33 & 35.14 & 0 & 40 & $<0.001$ \\
\hline & Kanamycin & 88.89 & 69.23 & 80 & - & 100 & $<0.001$ \\
\hline Phenicols & $\begin{array}{l}\text { Chlorampheni- } \\
\text { col }\end{array}$ & 55.56 & 56.86 & 100 & 33.33 & 100 & $<0.001$ \\
\hline Polymyxins & Colistin & 1.38 & 1.27 & 0 & 0 & 100 & $<0.001$ \\
\hline \multirow{6}{*}{$\begin{array}{l}\text { Quinolone } \\
\text { andFluoro- }\end{array}$} & Nalidixic acid & 89.61 & 95.83 & - & - & 100 & 0.03 \\
\hline & Quinolones & 85.11 & 78.95 & 63.89 & 100 & 70 & $<0.001$ \\
\hline & Pefloxacin & 86.86 & 78.95 & 65.71 & 100 & 70 & $<0.001$ \\
\hline & Levoxacin & 85.04 & 73.02 & 60 & 100 & 70 & $<0.001$ \\
\hline & Ofloxacin & 83.94 & 76.47 & 63.64 & 100 & 62.5 & $<0.001$ \\
\hline & Norfloxacin & 86.67 & 75 & 69.23 & 100 & 62.5 & $<0.001$ \\
\hline \multirow{2}{*}{ Cyclines } & Doxycycline & 97.47 & 89.83 & 96.3 & - & 100 & 0.004 \\
\hline & Tetracycline & 95.53 & 91.11 & 92.59 & 100 & 100 & 0.001 \\
\hline $\begin{array}{c}\text { Sulfonamides } \\
\text { and related }\end{array}$ & $\begin{array}{c}\text { Trimethoprim+ } \\
\text { sulfamethox- } \\
\text { azole }\end{array}$ & 98.15 & 98.31 & 94.44 & 100 & 100 & 0.015 \\
\hline
\end{tabular}

\section{Discussion}

A fact of increasing concern in the recent decades in clinical bacteriology is the emergence of multidrug resistance among Enterobacteriaceae strains isolated from patients. Addressing this problem should include the detection of resistant phenotypes. This has been initiated in many ways throughout the world. However, in Togo, there is a lack of published studies concerning the antibiotic resistance pattern. For this reason, our aim in this study was to evaluate the prevalence of Extended Spectrum Beta-Lactamases producing Enterobacteriaceae (ESBLE) and their susceptibility to several antibiotics. The identified strains included E. coli, $K$. pneumoniae, Enterobacter sp, Citrobacter diversus, C.freundii, P.mirabilis, P.vulgaris, K.oxytoca, E. coli A-D and Morganella morganii. Our results indicated that the global prevalence of ESBL producing strains was $22.44 \%$. This prevalence seemed to be very low according to the reported data from the studies conducted in some African countries such as Senegal (34\%) [24] and Egypt
(75.8\%) [25]. On the other hand the current value is higher than the value recorded in Cameroon (12\%) [10]. Analyzing the results by bacterial species, high prevalence was recorded for Enterobacter $s p$., followed by Klebsiella sp. and E. coli. Among ESBL-producing strains, the frequency of isolation of Enterobacter $s p$. was $13.27 \%$ versus $51.13 \%$ for E. coli strains, and $30.10 \%$ for strains of Klebsiella $s p$. The two last microorganisms occupied $81.23 \%$ of total ESBL-producing strains. Several studies have also highlighted the increasing prevalence of these two strains [25-27]. The abscesses and urinary tract infections were the main sources of ESBLE; an opposite result was obtained in a study in Saudi Arabia in 2005 where the urine contained more ESBL than suppurations [28]. Our results also showed that the blood samples contained $7.77 \%$ of ESBLE, a value similar to those reported by Wani et al. [29]. This study also revealed an unexpected antibiotic resistance pattern of the isolated strains. Thus, despite the high resistance to beta-lactam antibiotics, there was resistance to other families of antibiotics like aminoglycosides, tetracyclins and quinolones. Beta-lactamases 


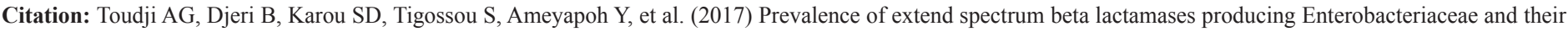
antibiotic susceptibility in Lomé, Togo. Asian J Life Sci 2017: AJLS101.

produced by these strains allowed them to inactivate all penicillins at a rate between 87.76 and $100 \%$. The results of this study susceptibility tests have confirmed this. All strains tested were sensitive to imipenem except the strains of E.coli and K.pneumoniae which displayed a very weak resistance to $0.68 \%$ and $3.6 \%$ respectively. Increasing resistance to this antibiotic expose the community to a lethal infection with ESBL-producing bacteria as carbapenems are the only subgroups of beta-lactams to be effective against these ESBLE producing strains. This observation was made on ESBL producing E. coli at Zou and Collines department in Benin (2007), where $5 \%$ resisted to imipenem. E. coli strains were susceptible at $83 \%$ to cefoxitin versus $81 \%$ for $K$. pneumoniae strains. This result is similar to the susceptibility studies of Spanu et al. in Italy in 2002, where approximately $80 \%$ of ESBL Enterobacteriaceae strains were susceptible to cefoxitin [30]. The molecule presents on the beta-lactam ring a methoxyl radical- $0-\mathrm{CH} 3$, that protects cefoxitin and imipenem against the action of the enzymes. According to Singleton et al., a molecule is protected from the action of enzymes by biochemical processes such as methylation which grafted a methyl on the beta-lactam ring. Hence, the beta-lactam ring was protected by methoxyl radicals who enabled these antibiotic molecules to escape from the action of beta-lactamases [31]. However, the low resistance observed is probably due to chromosomal over expression of cephalosporinase. This phenomenon is more observed in Klebsiella as outlined in the work of Stewards et al. [32]. ESBL producing Enterobacteriaceae resistance to aminoglycosides was lower than that observed with the beta-lactams. According to some authors, the misuse of antibiotics (in dosage and duration shortened treatment) results in the selection of resistant bacteria which have not been eliminated, to develop defense mechanisms of any kind including production enzymes [31]. These antibiotics are not often affordable in our regions like betalactams. Their toxicity is sometimes remarkable, and they are presented as injections thus limiting the self-medication. The strains of E. coli and Klebsiella species which do not produce beta-lactamases are naturally susceptible to aminoglycosides, quinolones. In this study, these strains exhibited a high resistance. For E.coli the resistance rates were $13.43 \%$ to $88.89 \%$ to aminoglycosides and $83.94 \%$ to $89.61 \%$ to quinolones. This quinolone resistance association was demonstrated in the work of Ahoyo et al. in Benin [11]. Klebsiella $s p$ also displayed a resistance of $4.23 \%$ to $94.64 \%$ to aminoglycosides and $75 \%$ to $95.83 \%$ to quinolones. These observations support the work of Tolun et al. in 2004 [33]. According to some authors, the plasmid carrying the beta-lactam resistance gene also would bring the QnrAquinolone resistance

\section{Conclusion}

The results of this study have shown an effective presence of ESBL in Togo's health facilities. The main bacterial species involved are E. coli and Klesiella sp. These microorganisms have developed strong resistance to several antibiotics, thus complicating the empirical prescription for clinicians. Further studies are needed to determine at the molecular level the types of beta lactamases produced by these bacteria.

\section{References}

1. Bradford PA (2001) Extended-spectrum ß-lactamases in the 21st century. Characterization, epidemiology, and detection of this important resistance Threat. Clin Microbiol Rev 14: 933-951.

2. Abdallah $B H$, Sahnoun $O$, Romdhane BF, Loussaïef C, Noomen $S$, et al. (2008) Profil de sensibilité aux antibiotiques des entérobactéries uropathogènes isolées dans la région de Monastir, Tunisie. Tun Infectiol 2: 5-8.

3. Rastogi V, Mishra PK, Bhatia S. (2012) Emerging antimicrobial resistance in hospital a threat to public health. Indian Journal of Community Health 24: 260-263.

4. Quincampoix JC, Mainardi JL (2001) Mechanisms underlying resistance of Gram-positive bacteria. Réanimation. 10: 267-275.

5. Luzzaro F, Mezzatesta M, Mugnaioli C, Perilli M, Stefani S, et al (2006) Trends in Production of Extended-Spectrum $\beta$-Lactamases among Enterobacteriaceae of Medical Interest: Report of the Secondltalian Nationwide Survey. J Clin Microbio 144: 1659-1664.

6. Paterson DL, Bonomo RA (2005) Extended-spectrum beta-lactamases: a clinical update. Clin Microbiol Rev 18: 657-686.

7. Rawat D, NairD (2010) Extended-spectrum $\beta$-lactamases in Gram Negative Bacteria. J Glob Infect Dis 2: 263-74.

8. Aminzadeh Z, Sadat-Kashi M, Sha'bani M (2008) Bacteriuria by extended-spectrum beta-lactamase-producing Escherichia coli and Klebsiellapneumoniae: isolates in a governmental hospital in South of Tehran. Iran J Kidney Dis 2: 197-200.

9. Irajian G, azayeri-Moghadas A, Beheshti A (2009) Prevalence of extended-spectrum betalactamase positive and multi-drug resistance pattern of Escherichia coli and Klebsiellapneumoniaeisolates. Iran J Microbiol 1: 49-53.

10. Gangoué-Piéboji J, Bedenic B, Koulla-Shiro S, Randegger C, AdiogoD, et al. (2005) Extended-spectrum- $\beta$-lactamase-producing Enterobacteriaceae in Yaounde, Cameroon. J Clin Microbiol 43: 3273-3277.

11. Ahoyo AT, Baba-Moussa L, Anago AE, Avogbe P, Missihoun TD, et al. (2007) Incidence d'infections liées à Escherichia coli producteur de bêta lactamases à spectre élargi au Centre hospitalier départemental du Zou et Collines au Bénin. Médecineet Maladies infectieuses 37: 746-752.

12. Dagnra AY, Tigossou S, Prince-David M (2000) Prevalence and antimicrobial susceptibility of bacterial meningitis. Med Mal Infect 30: 291-294.

13. Karou DS, Balaka A, Bamoké M, Tchelougou D, Assih M, et al. (2012) Epidemiology and antibiotic resistance of bacterial meningitis in $\mathrm{Da}-$ paong, northern Togo. Asian Pacific Journal of Tropical Medicine 5: 848-852.

14. Le Rémic Référentiel en Microbiologie médicale (bactériologie et mycologie. Montmorency: 2M2, $2^{\text {ème }}$ édition, 2004.

15. Barr JG, Hogg GM, Smyth ETM, Emmerson AM (1989) Comparison of identification of Enterobacteriaceae by API $20^{\mathrm{E}}$ and sensititre autoidentification system. J Clin Pathol 42: 649-652.

16. Awong-Taylor J, Craven KS, Griffiths L, Bass C, Muscarella M (2008) Comparison of biochemical and molecular methods for the identification of bacterial isolates associated with failed loggerhead sea turtle eggs. J Appl Microbiol 104: 1244-1251. 
Citation: Toudji AG, Djeri B, Karou SD, Tigossou S, Ameyapoh Y, et al. (2017) Prevalence of extend spectrum beta lactamases producing Enterobacteriaceae and their antibiotic susceptibility in Lomé, Togo. Asian J Life Sci 2017: AJLS101.

17. Overmanl TL, Plumley D, Overman SB, Goodman NL (1985) Comparison of the API Rapid E Four-Hour System with the API 20E Overnight System for the Identification of Routine Clinical Isolates of the Family Enterobacteriaceae. Journal of Clinical Microbiology 21: 542-545.

18. Jarlier V, Nicolas M, Fournier G, Phillipon A (1988) Extended broadspectrum beta-lactamases conferring transferable resistance to newer beta-lactam agents in Enterobacteriaceae: hospital prevalence and susceptibility patterns. Rev Infect Dis 10: 867-878.

19. (2015) Comité de l'antibiogramme de la société Française de Microbiologie.

20. Chees brough M (2000) District Laboratory practice in tropical countries. Press syndicate of the University of Cambridge, Cambridge United Kingdom, New York. 194-201.

21. Thomson RB, Miller JM (2003) Specimen collection, transport and processing: bacteriology. In: Murray PR, ed. Manual of Clinical Microbiology, 8th edition. Washington, ASM Press 286-330.

22. O'Hara CM, Weinstein MP, Miller JM (2003) Manual and automated systems for detection and identification of microorganisms. In: Murray PR, ed. Manual of Clinical Microbiology, 8th edition. Washington ASM Press 185-207

23. Clinical and Laboratory Standards Institute. 2008. Performance standards for Antimicrobial Disk Susceptibility Tests; Approved StandardNineteenth edition. CLSI document M100-A19. Clinical and Laboratory Standards Institute, Wayne, PA.

24. Fall B, Nadiele LP, Ndiaye KS, Diawara S, Ndiaye M, et al. (2013) Les Surveillance des Bact'eries Multir'esistantes (BMR) `a l'H'opital Principal de Dakar : Bilan sur 1 an.

25. Tansarli GS, Poulikakos P, Kapaskelis A, Falagas ME (2014) Proportion of extended-spectrum beta-lactamase (ESBL)-producingisolates among Enterobacteriaceae in Africa: evaluationof the evidence-systematic review. J Anti microb Chemother 69: 1177-1184.

26. Zarakolu P, Metan G, Hasçelik G, Akova M (2007). Prevalence of extended-spectrum beta-lactamases in nosocomial Escherichia coli and Klebsiella spp. Strains isolated from blood cultures. Mikrobiyol Bul. 41: 579-584.
27. Babypadmini S, Appalaraju B (2004) Extended spectrum beta-lactamases in urinary isolates of Escherichia coli and Klebsiellapneumoniae Prevalence and susceptibility pattern in a tertiary care hospital. Indian J Med Microbiol 22: 172-174.

28. Kader AA, Kumar A (2005) Prevalence and antimicrobial susceptibility of extended-spectrum beta-lactamase-producing Escherichia coli and Klebsiellapneumoniae in a general hospital. Ann Saudi Med 25: $239-42$.

29. Wani KA, Thakur MA, Siraj Fayaz A,Fomdia B, Gulnaz B, et al. (2009) Extended Spectrum -Lactamase Mediated Resistance in Escherichia Coli in a Tertiary Care Hospital. Int J Health Sci 3: 155-163.

30. Spanu T, Luzzaro F, Perilli M, Amicosante G, Toniolo A, et al. (2002) Occurrence of Extended-Spectrum $\beta$-Lactamases in Members of the Family Enterobacteriaceae in Italy: Implications for Resistance to $\beta$-Lactams and Other Antimicrobial Drugs. Antimicrob Agents Chemother 46: 196-202.

31. Singleton $P$ (2005) Bacteriology For medicine, biology and biotechnology. Dunod 6th edition Paris.

32. Stewart CD, Rasheed JK, Hubert SK, Biddle JW, Raney PM, (2001) Characterization of clinical isolates of Klebsiella pneumoniae from 19 laboratories using the National Committee for Clinical Laboratory Standards Extended-Spectrum ß-lactamase detection methods. J Clin Microbiol 39: 2864-2872.

33. Tolun V, Küçükbasmaci Ö, Törümküney-Akbulut D, Catal C, AngKüçüker M, et al. (2004) Relationship between ciprofloxacin resistance and extended-spectrum beta-lactamase production in Escherichia coli and Klebsiella pneumonia strains. Clin Microbiol Infect 10: 72-5.

34. Al-Jasser MA (2006) Extended-Spectrum Beta-Lactamases (ESBLs): A Global Problem. Department of Microbiology, Armed Forces Hospital, Riyadh, Saudi Arabia, Kuwait Medical Journal 38: 171-185. 